\title{
Totally laparoscopic proximal gastrectomy with double tract reconstruction: outcomes of 37 consecutive cases
}

\author{
Nam-ryong Choi, Min Ha Choi, Chang Seok Ko, Inseob Lee, Chung Sik Gong, Beom Su Kim \\ Department of Surgery, Asan Medical Center, University of Ulsan, College of Medicine, Seoul, Korea (South) \\ Videosurgery Miniinv 2020; 15 (3): 446-454 \\ DOI: https://doi.org/10.5114/wiitm.2020.94154
}

\begin{abstract}
Introduction: Proximal gastrectomy is an alternative treatment modality for gastric cancer in the upper third of the stomach. Though several reconstruction methods have been introduced, there is no standardization. We investigated the outcomes of laparoscopic proximal gastrectomy with double tract reconstruction (LPG-DTR).

Aim: To investigate the outcomes of LPG-DTR.

Material and methods: We evaluated 37 patients who underwent curative LPG with DTR between December 2013 and December 2018. Less than half of the proximal stomach was laparoscopically resected. We performed LPG-DTR after resection.

Results: A total of 37 patients were included in this study, 25 (70\%) of whom were male and 12 (30\%) of whom were female. Overall, 31 (83.7\%) patients were diagnosed with gastric cancer, 5 (13.5\%) with gastrointestinal stromal tumors, and 1 (2.8\%) with leiomyoma. There were 3 (9.6\%) complications. However, there were no complications of grade 3 or above. We did not observe postoperative mortality or recurrence after surgery. All patients underwent postoperative endoscopic surveillance successfully. None of the patients had postoperative reflux esophagitis or stenosis. The body weight and hemoglobin levels of the patients were lowest 12 months after surgery and gradually increased thereafter. Similarly, their vitamin $B_{12}$ levels were lowest 6 months after surgery. However, iron been increased after surgery until 24 months after surgery.

Conclusions: LPG-DTR is a favorable treatment modality for gastric cancer in the upper third of the stomach.
\end{abstract}

Key words: gastric cancer, proximal gastrectomy, double tract reconstruction.

\section{Introduction}

The incidence of gastric cancer in the upper portion of the stomach is continually increasing in Eastern and Western countries [1, 2]. Because early gastric cancer has an excellent long-term prognosis and the 5-year survival rate is higher than $90 \%$, quality of life after a gastrectomy is very important for patients $[3,4]$. Preserving a larger part of the stomach contributes to improving the postoperative nutritional status, maintaining body weight, and improving postoperative quality of life [5]. Therefore, proximal gastrectomy (PG) has been suggested as an alternative to total gastrectomy (TG) $[5,6]$. Several studies have proved that PG has advantages over TG - it is associated with a shorter operation time, earlier recovery, and better postoperative nutritional status [7-9]. The Japanese gastric cancer treatment guidelines recommend PG as an alternative procedure for early gastric cancer located in the upper portion of the stomach [10]. However, Kunisaki et al. reported that only a small proportion of institutes (21.8\%) perform PG for patients with early gastric cancer located in the upper third of the stomach [11].

\section{Address for correspondence}

Prof. Beom Su Kim MD, PhD, Department of Surgery, Asan Medical Center, University of Ulsan, College of Medicine, Seoul, Korea (South), e-mail: bskim0251@naver.com 
Accordingly, three types of reconstruction after PG have been introduced: esophagogastrostomy (EG stomy), jejunal interposition (JI), and double tract reconstruction (DTR). Although PG with EG stomy is a simple and feasible method, it is associated with a high risk of postoperative complications such as reflux esophagitis, which causes severe heartburn, chest pain, and regurgitation of sourness, stenosis, and residual food [5, 7, 12-19]. Hence many surgeons abandoned this reconstruction, and adopted tube-like stomach EG stomy [13, 16, 20-22]. They found that tube-like EG stomy had a lower incidence of stenosis and reflux esophagitis than traditional EG stomy. Recently, laparoscopic JI and DTR have been widely adopted for laparoscopic PG because many surgeons overcame several technical difficulties of totally laparoscopic total gastrectomy (TLTG).

Some studies have shown that LPG with DTR (PG-DT) could be used to avoid anastomotic complications $[23,24]$. In one study, the incidence of reflux symptoms, usage of proton pump inhibitors, and anastomotic strictures were significantly lower in the DTR than in the EG stomy group [23]. Li et al. performed a meta-analysis to compare the use of LPG-DTR and TG for proximal early gastric cancer [25]. They concluded that PG-DTR is comparable to TG for patients with proximal early gastric cancer, and reported that LPG-DT not only appears superior to TG in terms of preventing vitamin $B_{12}$ deficiency, but also does not increase the risks of anastomotic stricture and reflux esophagitis. However, a recent multicenter study conducted in Italy showed that PG is associated with a higher mortality rate and higher risks of reflux esophagitis and anastomotic stricture than TG [26].

\section{Aim}

This study was performed to investigate the feasibility, safety, and incidence of postoperative complications including reflux esophagitis and stricture of LPG with DRT.

\section{Material and methods}

We retrospectively collected and analyzed data on 37 patients who underwent curative LPG with DTR as treatment for upper third gastric cancer between December 2013 and December 2018. All patients underwent totally laparoscopic PG with intracorporeal DTR. We evaluated TNM stage using the classification guidelines presented in the eighth edition of the
American Joint Committee on Cancer Staging Manual. Numerous clinico-pathologic data were evaluated. Also, we evaluated postoperative complications (Clavien-Dindo classification), safety, effectiveness and feasibility. Additionally, the postoperative nutritional status and short-term oncologic outcomes of the patients were evaluated. This study was approved by the institutional review board (2019-0702).

\section{Surgical procedures}

Less than half of the proximal stomach was laparoscopically resected. We performed side-to-side intracorporeal esophagojejunostomy (EJ stomy) via the overlap method using a $45 \mathrm{~mm}$ linear stapler (Photo $1 \mathrm{~A}$ ). Following this, we closed the common hole transversely to prevent narrowing of the anastomosis between the esophagus and jejunum using $60 \mathrm{~mm}$ linear staplers and three stitches. Photo $1 \mathrm{~B}$ shows the final view after EJ stomy. We then performed gastrojejunostomy (GJ stomy) about 10$15 \mathrm{~cm}$ away from the EJ stomy site using two $60 \mathrm{~mm}$ linear staplers (Photos $1 \mathrm{C}$ and D). Lastly, intracorporeal jejunojejunostomy was performed about $20 \mathrm{~cm}$ away from the GJ stomy site using two $60 \mathrm{~mm}$ linear staplers (Photos $2 \mathrm{~A}$ and B). Photo $2 \mathrm{C}$ shows the final view after LPG with DTR. Photo 3 shows the endoscopic findings 6 months after LPG and DTR.

\section{Statistical analysis}

Numerical data were presented as mean \pm standard deviation. All statistical data were analyzed using SPSS 21.0 (SPSS Inc., Chicago, IL, USA). P-values $<0.05$ were considered to indicate statistically significant differences.

\section{Results}

\section{Basic clinicopathologic characteristics}

The clinicopathologic characteristics of all patients are summarized in Table I. A total of $37 \mathrm{pa}$ tients were included in this study, 25 (70\%) of whom were male and $12(30 \%)$ of whom were female. The mean age of the patients was $61.2 \pm 9.5$ years. Overall, 31 (83.7\%) patients were diagnosed with gastric cancer, 5 (13.5\%) with gastrointestinal stromal tumors (GISTs) and 1 (2.8\%) with leiomyoma. Moreover, 19 (51.3\%) had comorbidities and 4 (10.8\%) had undergone prior abdominal surgery. Two patients underwent cholecystectomy or hiatal hernia 
repair at the same time as LPG-DTR. There was no conversion to open surgery during the operation. All patients underwent LPG with DTR and all procedures were performed intracorporeally.

\section{Clinicopathologic outcomes of patients with gastric cancer}

The outcomes of the patients with gastric cancer are summarized in Table II. The mean operative tine was $171.4 \pm 29.4 \mathrm{~min}$. The mean length of hospital stay after surgery was $7.45 \pm 1.84$ days and the mean time to first flatus after surgery was $3.43 \pm 0.94$ days. Overall, 27 patients had stage IA gastric cancer and none had > stage 2A. We evaluated complications using the Clavien-Dindo classification; there were 3 (9.6\%) complications. However, there was no com- plication of grade 3 or above. We did not observe any postoperative mortality or recurrence after surgery.

\section{Endoscopic surveillance}

One patient with a GIST did not undergo endoscopic surveillance. Moreover, 3 patients were not evaluated for the distal stomach because the endoscopist incorrectly thought that they had undergone TG. The remaining 33 patients underwent complete postoperative endoscopic surveillance. Table III shows the pre- and postoperative endoscopic findings. A total of 63.6 patients had gastritis or atrophic gastritis before surgery, but only 13 (39.4\%) exhibited gastritis/atrophic gastritis during the postoperative endoscopic examination. Moreover, 3 (9\%) patients were diagnosed with reflux esophagitis during the preoperative endo-
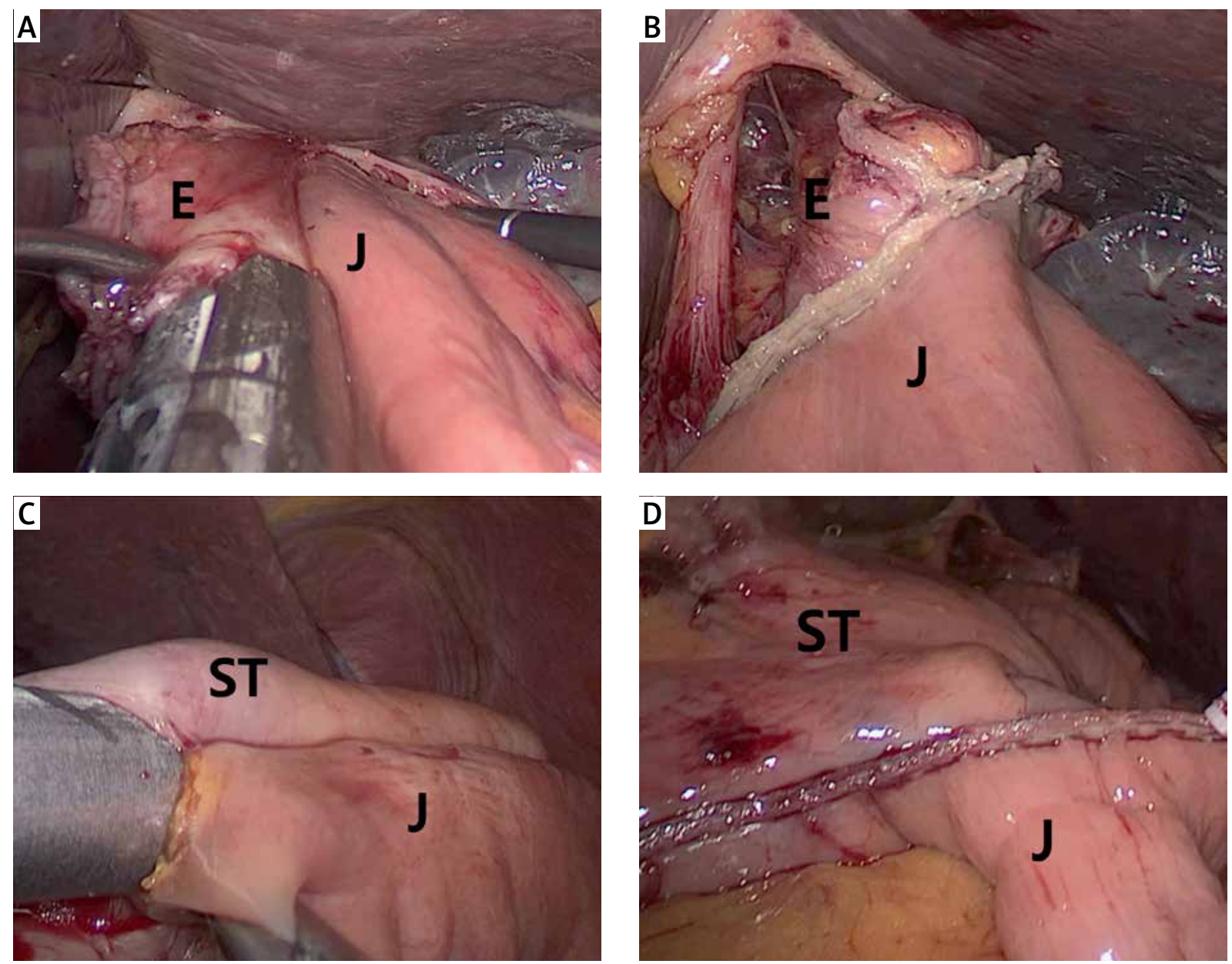

Photo 1. A - Intracorporeal esophagojejunostomy using $45 \mathrm{~mm}$ linear stapler, B - final anastomosis view after esophagojejunostomy, C - intracorporeal gastrojejunostomy using $60 \mathrm{~mm}$ linear staplers, D - final anastomosis view after gastrojejunostomy

E-esophagus, J-jejunum, ST-stomach. 

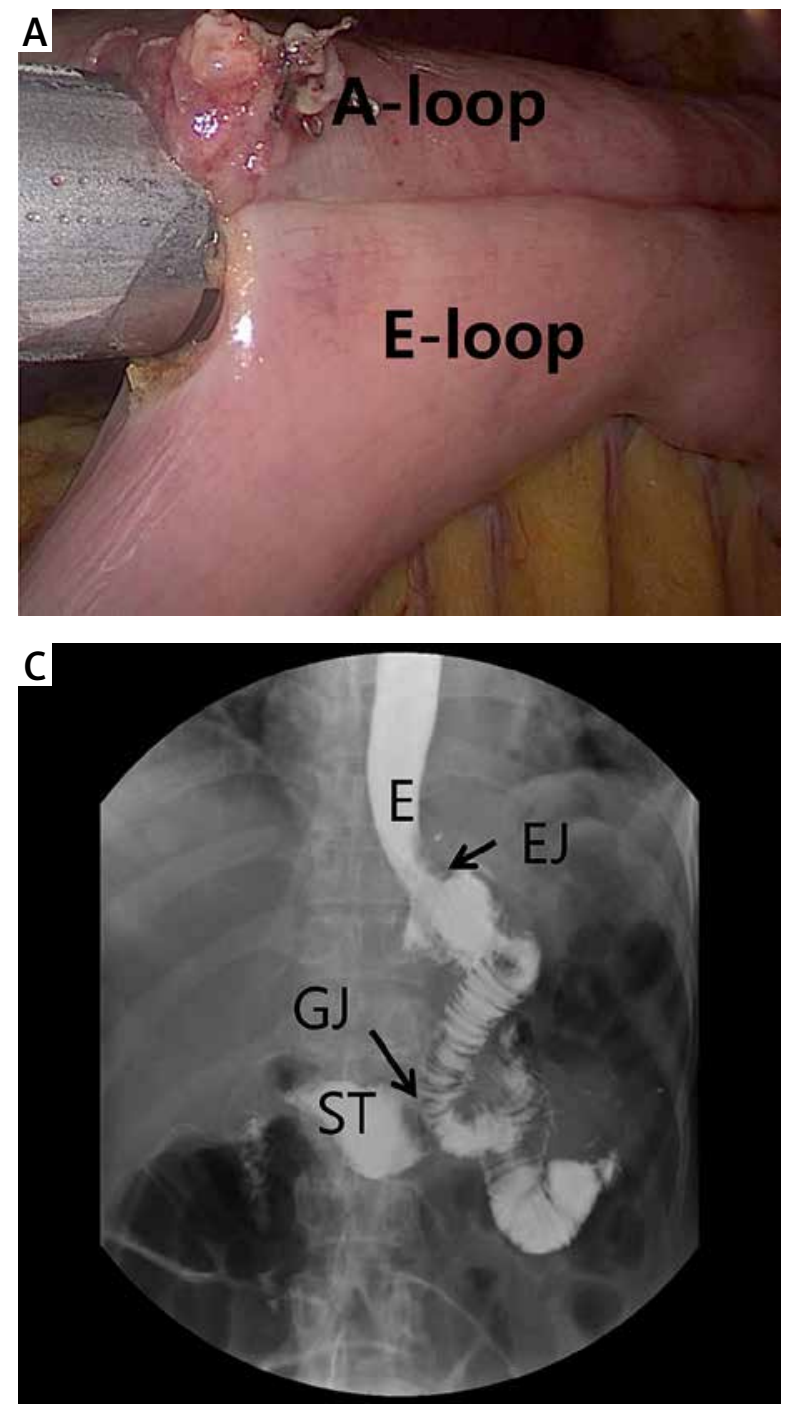

scopic examination, but none exhibited reflux esophagitis after surgery. In addition, none of the 33 patients developed postoperative reflux esophagitis. Moreover, we did not observe stenosis or stricture at the EJ stomy or GJ stomy site. One patient was diagnosed with a gastric ulcer and another with a duodenal ulcer. Both were successfully treated with medication.

\section{Nutritional outcomes and body weight changes}

The postoperative nutritional outcomes and body weight changes of the patients are summarized in Table IV and Figures 1 and 2. Maximum weight loss was observed 1 year after surgery $(6.9 \mathrm{~kg}, 10.5 \%)$. Following this, the body weight of the patients gradually increased and recovered to $96.8 \%$ of their preopera-

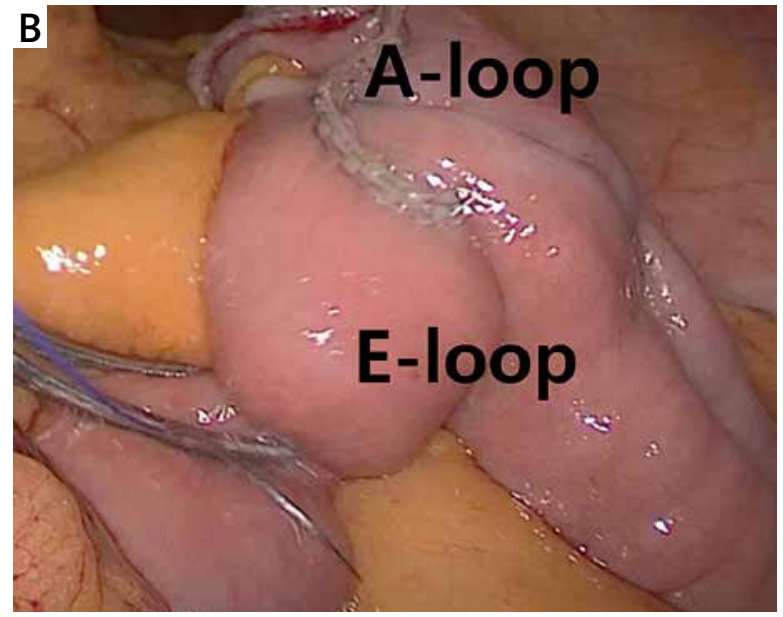

Photo 2. A - Intracorporeal jejunojejunostomy using $60 \mathrm{~mm}$ linear stapler, B - final anastomosis view after jejunojejunostomy, $\mathbf{C}$ - upper gastrointestinal series after surgery

A-loop-afferent loop, E-loop-efferent loop, EJ-esophagojejunostomy, GJ - gastrojejunostomy.

tive body weight 3 years after surgery. Likewise, serum hemoglobin level decreased maximally $(0.8 \mathrm{~g} / \mathrm{dl}$, $5.9 \%) 1$ year after surgery and increased thereafter, and it was higher than preoperative hemoglobin level from 2 years after surgery. The iron levels of the patients increased after surgery and were highest 2 years after surgery. However, the vitamin $B_{12}$ levels of the patients were lowest 6 months after surgery and fluctuated thereafter. In contrast, albumin level was higher than the preoperative level from 6 months after surgery.

\section{Discussion}

PG has gradually replaced TG as the surgical method of choice for gastric cancer in the upper third of 

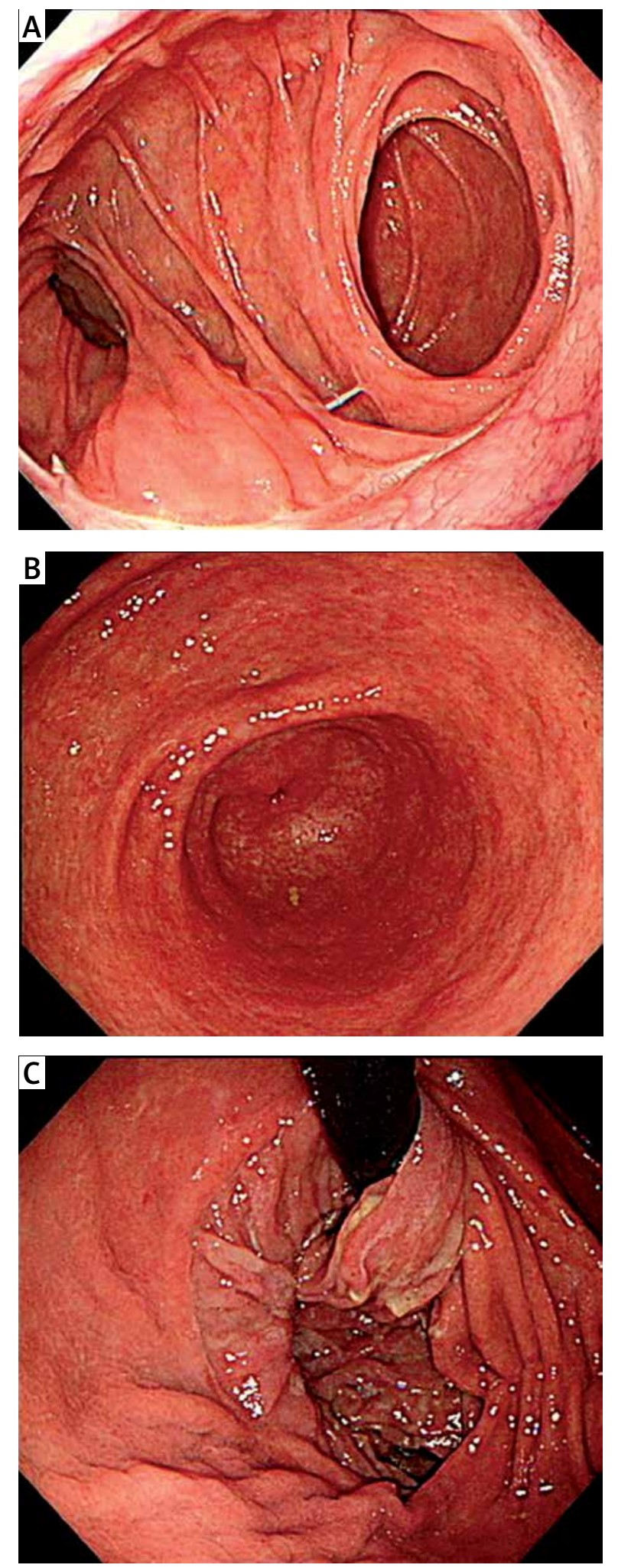

Photo 3. Endoscopic findings. A - Esophagojejunostomy site, B - distal remnant stomach, $\mathbf{C}$ - gastrojejunostomy site
Table I. Clinicopathologic characteristics of all patients $(n=37)$

\begin{tabular}{|c|c|}
\hline Patient characteristics & $\begin{array}{l}\text { Number }(\%) \text { or mean } \\
\pm \text { standard deviation }\end{array}$ \\
\hline \multicolumn{2}{|l|}{ Sex: } \\
\hline Male & $25(70.0)$ \\
\hline Female & $12(30.0)$ \\
\hline Age [years] & $61.2 \pm 9.5$ \\
\hline BMI $\left[\mathrm{kg} / \mathrm{m}^{2}\right]$ & $24.7 \pm 2.9$ \\
\hline \multicolumn{2}{|l|}{ Pathology: } \\
\hline Gastric cancer & $31(83.7)$ \\
\hline Gastrointestinal stromal tumor & $5(13.5)$ \\
\hline Leiomyoma & $1(2.8)$ \\
\hline \multicolumn{2}{|l|}{ ASA score: } \\
\hline 1 & $6(16.2)$ \\
\hline 2 & $31(83.8)$ \\
\hline 3 & $0(0)$ \\
\hline \multicolumn{2}{|l|}{ Presence of comorbidities: } \\
\hline Yes & $19(51.3)$ \\
\hline No & $18(48.7)$ \\
\hline \multicolumn{2}{|l|}{ History of abdominal surgery: } \\
\hline Yes & $4(10.8)$ \\
\hline No & $33(89.2)$ \\
\hline \multicolumn{2}{|l|}{ Combined surgery: } \\
\hline Yes & $2(5.5)$ \\
\hline No & $35(94.5)$ \\
\hline Conversion to open surgery & 0 \\
\hline
\end{tabular}

$B M I$ - body mass index, ASA - American Society of Anesthesiologists.

the stomach because PG has similar oncological outcomes to TG and the reservoir capacity of the stomach [27-29]. It is well established that early gastric cancer located in the upper third of the stomach is rarely associated with lymph node metastasis at number four $\mathrm{d}$, fiver and six [10, 30, 31]. Thus, the Japanese Gastric Cancer Association and Korean Gastric Cancer Association recommend that PG be used to treat early gastric cancer located in the upper third of the stomach $[10,32]$.

Laparoscopic total gastrectomy (LTG) was first reported in 1999 [33]. It is practiced less widely 
Table II. Clinicopathologic outcomes of patients with gastric cancer $(n=31)$

\begin{tabular}{|c|c|}
\hline Parameter & Results \\
\hline Operative time [min] & $171.4 \pm 29.36$ \\
\hline Length of hospital stay after surgery [days] & $7.45 \pm 1.84$ \\
\hline Time to first flatus after surgery [days] & $3.43 \pm 0.94$ \\
\hline \multicolumn{2}{|l|}{ T stage: } \\
\hline 1 & $27(87.1)$ \\
\hline 2 & $3(9.6)$ \\
\hline 3 & $1(3.3)$ \\
\hline 4 & $0(0)$ \\
\hline \multicolumn{2}{|l|}{ N stage: } \\
\hline 0 & $31(100)$ \\
\hline $1 / 2 / 3$ & $0(0)$ \\
\hline \multicolumn{2}{|l|}{ AJCC TNM stage: } \\
\hline $1 \mathrm{~A}$ & $27(87.1)$ \\
\hline $1 \mathrm{~B}$ & $3(9.6)$ \\
\hline $2 \mathrm{~A}$ & $1(3.3)$ \\
\hline$>2 \mathrm{~A}$ & $0(0)$ \\
\hline Retrieved lymph nodes & $30.92 \pm 14.18$ \\
\hline Clavien-Dindo classification (complication): & $3(9.6)$ \\
\hline 1 & 0 \\
\hline 2 & $3(9.6)$ \\
\hline$>3$ & 0 \\
\hline Postoperative mortality & 0 \\
\hline Recurrence & 0 \\
\hline
\end{tabular}

AJCC - American Joint Committee on Cancer.

and is more challenging to perform because the procedure is associated with a high risk of bleeding and a technically demanding anastomosis, all within a narrow operating field [34-36]. However, as a result of technical advances and improved
Table III. Comparison of preoperative and postoperative endoscopic findings $(n=33)$

\begin{tabular}{|lcc|}
\hline Parameter & Preoperative & Postoperative \\
\hline Gastritis/atrophic gastritis & $21(63.6)$ & $13(39.4)$ \\
\hline Reflux esophagitis & $3(9.0)$ & 0 \\
\hline $\begin{array}{l}\text { Stenosis (stricture) at the } \\
\text { EJ stomy or GJ stomy site }\end{array}$ & 0 & 0 \\
\hline Gastric ulcer & 0 & $1(3.0)$ \\
\hline Duodenal ulcer & & $1(3.0)$ \\
\hline
\end{tabular}

EJ stomy - esophagojejunostomy, GJ stomy - gastrojejunostomy.

instrumentation, various techniques of intracorporeal EJ stomy have been introduced. Thus, TLTG was widely accepted for gastric cancer in the upper third of the stomach and the use of LPG has gradually increased. Recently, a number of studies comparing TLTG and conventional open TG for gastric cancer located in the upper third of the stomach have shown it to be feasible, effective, and safe [22, 37, 38]. In this study, we performed all PG using totally laparoscopic surgery with intracorporeal anastomosis without postoperative mortality or severe complications.

We did not investigate PG with EJ stomy because a number of studies showed that PG with EG stomy was associated with a higher incidence of complications such as reflux, stenosis, and stricture than TG $[15,23,39]$. Furthermore, several studies reported that there was no significant difference in surgical outcomes between LPG with DTR and LTG [3, 24, 25, 27, 40-42]. In a previous study, LPG with DTR did not increase the incidences of reflux esophagitis and anastomotic stenosis compared to LTG. Moreover, the incidence rates of reflux esophagitis and anastomotic stenosis were lower in the PG with DTR group than in the PG with EJ stomy group [11]. Thus, we concluded that LPG with DTR

Table IV. Nutritional outcomes and body weight changes after surgery

\begin{tabular}{|lccccc|}
\hline Characteristic & Pre-operative & $\begin{array}{c}6 \text { months } \\
(\text { POM })\end{array}$ & $\begin{array}{c}12 \text { months } \\
(\text { POM })\end{array}$ & $\begin{array}{c}24 \text { months } \\
\text { (POM) }\end{array}$ & $\begin{array}{c}36 \text { months } \\
(\text { POM })\end{array}$ \\
\hline Body weight $[\mathrm{kg}]$ & $65.4 \pm 9.1$ & $58.9 \pm 8.2$ & $58.5 \pm 8.8$ & $60.4 \pm 8.8$ & $63.4 \pm 10.1$ \\
\hline Hemoglobin $[\mathrm{g} / \mathrm{dl}]$ & $13.5 \pm 1.7$ & $13.0 \pm 1.2$ & $12.7 \pm 2.0$ & $14.2 \pm 6.6$ & $15.2 \pm 7.7$ \\
\hline Iron $[\mathrm{\mu g} / \mathrm{dl}]$ & $91.3 \pm 21.5$ & $101.7 \pm 34.8$ & $102.3 \pm 32.1$ & $113.2 \pm 34.8$ & $101.1 \pm 46.5$ \\
\hline Vitamin $\mathrm{B}_{12}[\mathrm{pg} / \mathrm{dl}]$ & $714.8 \pm 388.3$ & $593.9 \pm 378.4$ & $690.6 \pm 509.8$ & $606.0 \pm 304.4$ & $705.6 \pm 341.6$ \\
\hline Albumin $[\mathrm{g} / \mathrm{dll}]$ & $3.9 \pm 0.4$ & $4.0 \pm 0.3$ & $4.0 \pm 0.3$ & $3.9 \pm 0.4$ & $4.1 \pm 0.3$ \\
\hline
\end{tabular}

POM - post-operative months. 
A

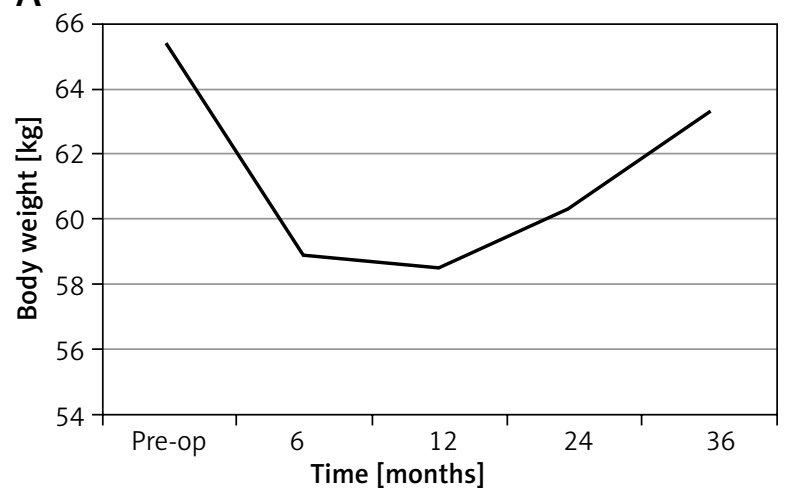

B

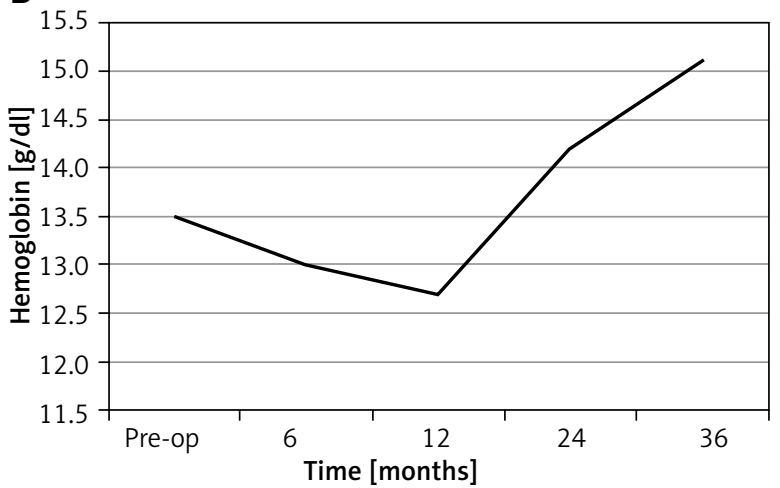

Figure 1. Body weight (A) and hemoglobin (B) changes after surgery

Pre-op-preoperative.

A

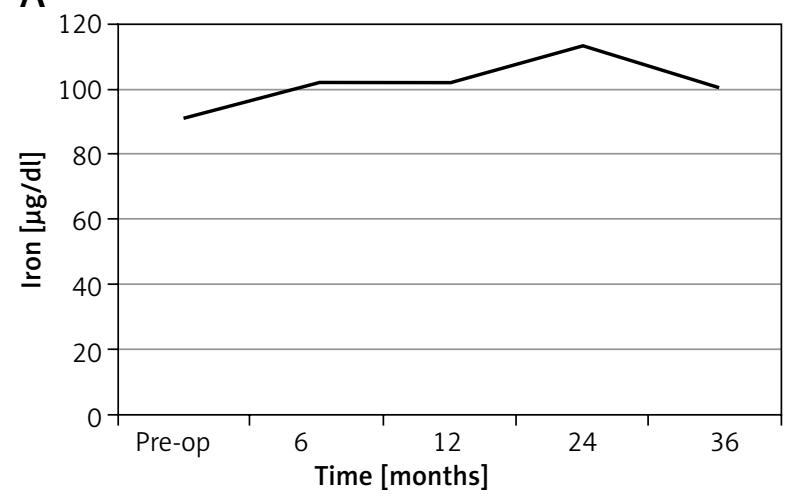

B

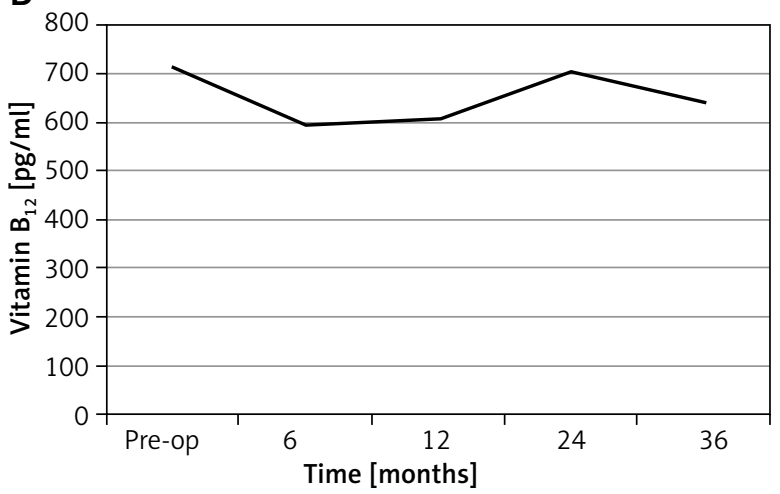

Figure 2. Serum iron (A) and vitamin $B_{12}(B)$ changes after surgery

Pre-op-preoperative.

is a feasible and safe treatment option for early gastric cancer located in the upper third of the stomach.

Quality of life including nutritional issues is an important problem especially for patients with early gastric cancer or benign disease. Many studies have reported that LPG had nutritional benefits and a good quality of life. Kim et al. reported that patients who underwent LPG with DTR had higher iron and vitamin $B_{12}$ absorption rates than those who underwent LTG [41]. Jung et al. showed that the body weight change in LPG with DTR is lower and the vitamin $B_{12}$ level is higher than the LTG group [27]. Sugiyama et al. observed that the body weight and skeletal muscle index reduction rates were lower in the LPG-DT group than in the LTG group [42]. Recently, Tanioka et al. reviewed 11 articles (336 underwent LPG and 547 underwent LTG) to evaluate surgical outcome and nutritional outcomes [43]. The
LTG group had a significantly lower body weight and LPG had a weighted mean difference. Also, total protein, albumin and the total lymphocyte count were less likely to decrease in the LPG group.

The present study has some limitations. First, this was a retrospective study performed at a single institute. Second, the number of enrolled patients was relatively small. Third, we did not evaluate longterm oncologic outcomes. Lastly, this was a single arm study.

\section{Conclusions}

We observed that totally laparoscopic proximal gastrectomy with double tract reconstruction had favorable outcomes and was feasible and safe. Therefore, we recommend its use to treat early gastric cancer or benign disease in the upper third of the stomach. 


\section{Conflict of interest}

\section{The authors declare no conflict of interest.}

\section{References}

1. Deans C, Yeo MS, Soe MY, et al. Cancer of the gastric cardia is rising in incidence in an Asian population and is associated with adverse outcome. World I Surg 2011; 35: 617-24.

2. Steevens J, Botterweck AA, Dirx MJ, et al. Trends in incidence of oesophageal and stomach cancer subtypes in Europe. Eur J Gastroenterol Hepatol 2010; 22: 669-78.

3. Furukawa H, Hiratsuka M, Imaoka S, et al. Limited surgery for early gastric cancer in cardia. Ann Surg Oncol 1998; 5: 338-41.

4. Takiguchi S, Masuzawa T, Hirao M, et al. Pattern of surgical treatment for early gastric cancers in upper third of the stomach. Hepatogastroenterology 2011; 58: 1823-7.

5. Katai H, Morita S, Saka M, et al. Long-term outcome after proximal gastrectomy with jejunal interposition for suspected early cancer in the upper third of the stomach. Br J Surg 2010; 97: 558-62.

6. Katai H, Sano T, Fukagawa T, et al. Prospective study of proximal gastrectomy for early gastric cancer in the upper third of the stomach. Br J Surg 2003; 90: 850-3.

7. Masuzawa T, Takiguchi S, Hirao M, et al. Comparison of perioperative and long-term outcomes of total and proximal gastrectomy for early gastric cancer: a multi-institutional retrospective study. World J Surg 2014; 38: 1100-6.

8. Nozaki I, Hato S, Kobatake T, et al. Long-term outcome after proximal gastrectomy with jejunal interposition for gastric cancer compared with total gastrectomy. World J Surg 2013; 37: 558-64.

9. Shiraishi N, Adachi Y, Kitano S, et al. Clinical outcome of proximal versus total gastrectomy for proximal gastric cancer. World J Surg 2002; 26: 1150-4.

10. Japanese Gastric Cancer Association. Japanese gastric cancer treatment guidelines 2014 (ver. 4). Gastric Cancer 2017; 20 1-19.

11. Kunisaki C, Akiyama H, Nomura M, et al. Surgical outcomes for early gastric cancer in the upper third of the stomach. J Am Coll Surg 2005; 200: 15-9.

12. Hsu CP, Chen CY, Hsieh YH, et al. Esophageal reflux after total or proximal gastrectomy in patients with adenocarcinoma of the gastric cardia. Am J Gastroenterol 1997; 92: 1347-50.

13. Adachi Y, Inoue T, Hagino Y, et al. Surgical results of proximal gastrectomy for early-stage gastric cancer: jejunal interposition and gastric tube reconstruction. Gastric Cancer 1999; 2: 40-5.

14. Ahn SH, Lee JH, Park DJ, et al. Comparative study of clinical outcomes between laparoscopy-assisted proximal gastrectomy (LAPG) and laparoscopy-assisted total gastrectomy (LATG) for proximal gastric cancer. Gastric Cancer 2013; 16: 282-9.

15. An JY, Youn HG, Choi MG, et al. The difficult choice between total and proximal gastrectomy in proximal early gastric cancer. Am J Surg 2008; 196: 587-91.

16. Chen XF, Zhang B, Chen ZX, et al. Gastric tube reconstruction reduces postoperative gastroesophageal reflux in adenocarcinoma of esophagogastric junction. Dig Dis Sci 2012; 57: 738-45.
17. Sakuramoto S, Yamashita K, Kikuchi S, et al. Clinical experience of laparoscopy-assisted proximal gastrectomy with Toupet-like partial fundoplication in early gastric cancer for preventing reflux esophagitis. J Am Coll Surg 2009; 209: 344-51.

18. Seshimo A, Miyake K, Amano K, et al. Clinical outcome of esophagogastrostomy after proximal gastrectomy for gastric cancer. Hepatogastroenterology 2013; 60: 616-9.

19. Tokunaga M, Ohyama S, Hiki N, et al. Endoscopic evaluation of reflux esophagitis after proximal gastrectomy: comparison between esophagogastric anastomosis and jejunal interposition. World J Surg 2008; 32: 1473-7.

20. Aihara R, Mochiki E, Ohno T, et al. Laparoscopy-assisted proximal gastrectomy with gastric tube reconstruction for early gastric cancer. Surg Endosc 2010; 24: 2343-8.

21. Hosogi H, Yoshimura F, Yamaura T, et al. Esophagogastric tube reconstruction with stapled pseudo-fornix in laparoscopic proximal gastrectomy: a novel technique proposed for Siewert type II tumors. Langenbecks Arch Surg 2014; 399: 517-23.

22. Mochiki E, Toyomasu Y, Ogata K, et al. Laparoscopically assisted total gastrectomy with lymph node dissection for upper and middle gastric cancer. Surg Endosc 2008; 22: 1997-2002.

23. Aburatani T, Kojima K, Otsuki S, et al. Double-tract reconstruction after laparoscopic proximal gastrectomy using detachable ENDO-PSD. Surg Endosc 2017; 31: 4848-56.

24. Nomura E, Kayano $H$, Lee SW, et al. Functional evaluations comparing the double-tract method and the jejunal interposition method following laparoscopic proximal gastrectomy for gastric cancer: an investigation including laparoscopic total gastrectomy. Surg Today 2019; 49: 38-48.

25. Li S, Gu L, Shen Z, et al. A meta-analysis of comparison of proximal gastrectomy with double-tract reconstruction and total gastrectomy for proximal early gastric cancer. BMC Surg 2019; 19: 117.

26. Rosa F, Quero G, Fiorillo C, et al. Total vs proximal gastrectomy for adenocarcinoma of the upper third of the stomach: a propensity-score-matched analysis of a multicenter western experience (On behalf of the Italian Research Group for Gastric Cancer-GIRCG). Gastric Cancer 2018; 21: 845-52.

27. Jung DH, Lee Y, Kim DW, et al. Laparoscopic proximal gastrectomy with double tract reconstruction is superior to laparoscopic total gastrectomy for proximal early gastric cancer. Surg Endosc 2017; 31: 3961-9.

28. Harrison LE, Karpeh MS, Brennan MF. Total gastrectomy is not necessary for proximal gastric cancer. Surgery 1998; 123: 127-30.

29. Yoo $\mathrm{CH}$, Sohn BH, Han WK, et al. Long-term results of proximal and total gastrectomy for adenocarcinoma of the upper third of the stomach. Cancer Res Treat 2004; 36: 50-5.

30. Buhl K, Schlag P, Herfarth C. Quality of life and functional results following different types of resection for gastric carcinoma. Eur J Surg Oncol 1990; 16: 404-9.

31. Kaibara N, Nishimura O, Nishidoi H, et al. Proximal gastrectomy as the surgical procedure of choice for upper gastric carcinoma. J Surg Oncol 1987; 36: 110-2.

32. Guideline Committee of the Korean Gastric Cancer Association (KGCA), Development Working Group \& Review Panel. Korean Practice Guideline for Gastric Cancer 2018: an evidence-based, multi-disciplinary approach. J Gastric Cancer 2019; 19: 1-48. 
33. Uyama I, Sugioka A, Fujita J, et al. Laparoscopic total gastrectomy with distal pancreatosplenectomy and D2 lymphadenectomy for advanced gastric cancer. Gastric Cancer 1999; 2: 230-4.

34. Eom BW, Kim YW, Lee SE, et al. Survival and surgical outcomes after laparoscopy-assisted total gastrectomy for gastric cancer: case-control study. Surg Endosc 2012; 26: 3273-81.

35. Usui S, Yoshida T, Ito K, et al. Laparoscopy-assisted total gastrectomy for early gastric cancer: comparison with conventional open total gastrectomy. Surg Laparosc Endosc Percutan Tech 2005; 15: 309-14.

36. Xiong JJ, Nunes QM, Huang W, et al. Laparoscopic vs open total gastrectomy for gastric cancer: a meta-analysis. World I Gastroenterol 2013; 19: 8114-32.

37. Sakuramoto S, Kikuchi S, Futawatari N, et al. Laparoscopy-assisted pancreas- and spleen-preserving total gastrectomy for gastric cancer as compared with open total gastrectomy. Surg Endosc 2009; 23: 2416-23.

38. Topal B, Leys E, Ectors N, et al. Determinants of complications and adequacy of surgical resection in laparoscopic versus open total gastrectomy for adenocarcinoma. Surg Endosc 2008; 22: 980-4.

39. Nishigori T, Okabe H, Tsunoda S, et al. Superiority of laparoscopic proximal gastrectomy with hand-sewn esophagogastrostomy over total gastrectomy in improving postoperative body weight loss and quality of life. Surg Endosc 2017; 31 3664-72.

40. Cho M, Son T, Kim HI, et al. Similar hematologic and nutritiona outcomes after proximal gastrectomy with double-tract reconstruction in comparison to total gastrectomy for early upper gastric cancer. Surg Endosc 2019; 33: 1757-68.

41. Kim DJ, Kim W. Laparoscopy-assisted proximal gastrectomy with double tract anastomosis is beneficial for vitamin B12 and iron absorption. Anticancer Res 2016; 36: 4753-8.

42. Sugiyama M, Oki E, Ando K, et al. Laparoscopic proximal gas trectomy maintains body weight and skeletal muscle better than total gastrectomy. World I Surg 2018; 42: 3270-6.

43. Tanioka T, Waratchanont R, Fukuyo R, et al. Surgical and nutritional outcomes of laparoscopic proximal gastrectomy versus total gastrectomy: a meta-analysis. Surg Endosc 2020; 34 1061-9.

Received: 6.03.2020, accepted: 16.03.2020. 